\title{
The Influence of Parenting and Friendship on Self-Esteem in Adolescents
}

\author{
Rini Sugiarti ${ }^{1 *}$, Erwin Erlangga ${ }^{1}$, Purwaningtyastuti Purwaningtyastuti ${ }^{1}$, Fendy Suhariadi ${ }^{2}$ \\ ${ }^{1}$ Department of Psychology, Universitas Semarang, Semarang, Indonesia; ${ }^{2}$ Head of Doctoral Program, Human Resources \\ Development Postgraduate School, Faculty of Psychology, Universitas Airlangga, Surabaya, Indonesia
}

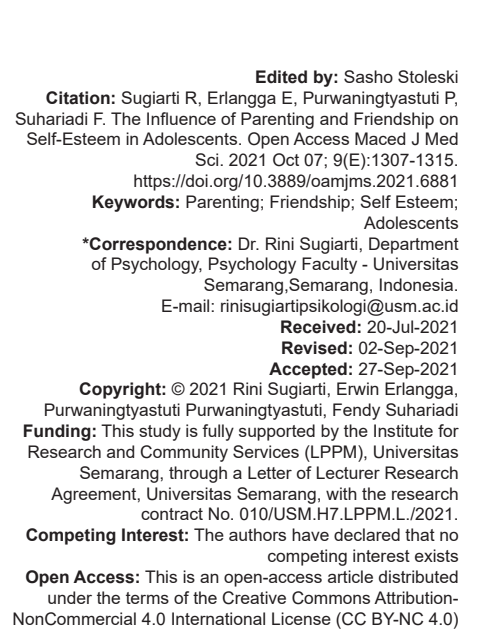

\section{Abstract}

BACKGROUND: Studies in psychology often discuss adolescents with their strong self-esteem as individuals who know themselves. Self-esteem development in adolescents. These adolescents begin to understand the changes of personality development starting from the cognitive aspect or thoughts, emotion, feeling, social, and physical aspects.

AIM: This study consistently aimed at finding comprehensive evidence that positive parenting and friendship affect self-esteem in adolescents.

METHODS: The population of this study was adolescents, namely 173 senior high school students consisting of 72 males and 100 females who were involved and participated in this study. The data analysis, in this study, was the 2 predictors for linear regression analysis.

RESULTS: The results showed that parenting and friendship simultaneously influenced self-esteem formation in adolescents. Partially, the result of this study also showed that parenting affected self-esteem formation in adolescents.

CONCLUSION: In conclusion, friendship showed a significant effect on self-esteem formation in adolescents. Thus the hypotheses in this study were accepted.

\section{Introduction}

Personality strength will be a foundation for adolescents to have a social life. Strong personalities will make the adolescents able to prepare for their adulthood in a better way. Personality functions as someone's identity or the nation's identity, in which the characteristics are reflected in the form of knowledge, behavior, emotions, values, and beliefs as the esteem (recognition) in oneself [1]. Self-esteem is the implementation form of, for instance, personality. Self-esteem generally refers to the assessment of oneself and it is about how far someone has positive feelings toward him/herself, having something valuable (precious) from him/herself, and believing the existence of precious, prestigious, or valuable in him/ herself [2]. Self-esteem, in its development, is strongly influenced by various aspects, both internally and externally, from the outside of the adolescents, such as the comfort of social relations, education, physical health, mental balance, and other important things.

\section{Parenting and self-esteem in adolescents}

The factors affecting adolescent development are environmental factors and heredity. Environmental factor, in this case, includes families and friends from a fellowship. Furthermore, it [3] was also stated several studies on psychosocial development in adolescents that were strongly influenced by the social context. For example, the parents-children positive relationship, prosocial behavior of peers, and the school situation are strongly related to the psychosocial maturity during adolescence and it will form their personalities. The theory by Bronfenbrenner stated that the family as a part of social agents is an environmental system that is known as a microsystem. As a microsystem, the family strongly and directly affects the quality of the children's personality development [4]. In the reality, parenting performed by parents gives color toward the development of personality and behavior that are strongly needed by the children for adulthood life when having interaction with the society widely [5].

The adolescents' self-esteem, in its development, is strongly affected and formed by interaction with other people [6]. Furthermore, selfesteem in adolescents is affected by the quality of interaction with parents. They play a big role in selfesteem development in adolescents. The way parents interact in daily activities and treat adolescents forms their self-esteem. Specifically, a warm parenting style 
that is full of acceptance will be a strong foundation in self-esteem development in adolescents. The parents' support in helping the adolescents when facing many problems, either in social scope or related to academic activities, will increase their self-esteem. The research data showed that the adolescents who receive warmth and are close to their parents will increase their self-esteem [7]. For the adolescents, the closeness to parents that affects the comfort, trust, and positive communication between them will make the adolescents able to have a good interaction with the surrounding environment. Such a development is vital for the growth of self-esteem in adolescents. The adolescents who grow up in a family with coziness and positive treatment will be the adolescents who can develop a good relation in society [8]. The studies also showed that the adolescents who grew up in families with positive parenting would be able to develop their self-esteem well [9]. The empirical evidence showed the relevancy between parenting and self-esteem in adolescents. In a nutshell, the adolescents who receive a positive closeness from their parents will also show positive self-esteem [10]. Several studies showed a condition that the neighborhood as a social agent supported and played a role in developing or maintaining the adolescents' personalities; whereby, in this context, it is the parenting. An empirical study conducted by also showed that an environment where adolescents live has an important role in structuring their personalities [11].

\section{Friendship and self-esteem in adolescents}

Besides families or particularly parenting, the empirical evidence showed the existence of significant variability in the development level and rate of psychosocial maturity in adolescence through a friendship. The adolescents will be able to develop their personalities through the friendship media. This includes the feeling of appreciating each other, and even the conflict between feelings and self-esteem. This can happen because, during adolescence, they begin to develop social relations, social identity, and their role functions. Studies in psychology frequently discuss adolescents with their strong self-esteem as individuals that know themselves [12]. These adolescents begin to understand the changes in the personality development of cognitive aspects or thoughts, emotions and feelings, as well as social and physical aspects. The recent study on adolescents' self-esteem, focusing more on those topics, contributes to self-esteem development, such as self-incongruence, self-esteem stability, motivation, and self-regulation. Therefore, holistic selfesteem development, including thoughts, emotions, social, physical, and mental aspects, helps generate a high-quality personal characteristic. In a nutshell, selfesteem development is the vital aspect that should be emphasized in structuring personalities through social interaction in adolescents.

\section{The current study}

Self-esteem is formed and developed since the adolescents grow up in families, and it is more developed when the adolescents extend their socialization, such as along with their friends from a fellowship. Based on the statement, the research related to self-esteem becomes an interesting topic to be analyzed deeply.

The objective of this study was to simultaneously identify the influence of parenting and friendship on self-esteem in adolescents. Partially, this study also tried to empirically examine the influence of parenting on self-esteem in adolescents [13], and the influence of friendship on self-esteem in adolescents. Furthermore, this study also tried to examine the parenting indicator consisting of the parents' cooperation [10], being tolerant with children, and warmth, as well as the friendship indicator consisting of support/care, recreation, help and guidance, intimate exchanges, conflict \& betrayal, and conflict resolution that are associated with selfesteem in adolescents consisting of personal interest, friendship, school, and parents [14].

\section{Methods}

\section{Sample}

The sampling technique, in this study, was cluster random sampling. Cluster random sampling is a sampling technique where the researcher divides the population into some separated group known as cluster/class. From these clusters, some samples were selected randomly. In this study, the selected class was class $X\left(10^{\text {th }}\right.$ grade $)$ and class $X I\left(11^{\text {th }}\right.$ grade $)$. The total sample from class $X$ was 34 students and class $X I$ was 138 students. Therefore, the overall total sample was 172 students consisting of 72 male students and 100 female students.

\section{Procedure}

This study was conducted from January 2021 to April 2021. As many as 172 students participated as the respondent received 3 measurement scales in the form of Google form. The three measurement scales were the Parenting Scale, Friendship Scale, and SelfEsteem Scale. Before completing the three scales, the respondents received an explanation related to the objective of this study. Furthermore, the respondents were convinced that the process of completing the scales up to collecting the result did not affect the learning assessment in the class. The respondents also obtained instruction related to the technical administration or the completion instruction.

The process of completing the scales was conducted during the learning process in the class and 
required around $45 \mathrm{~min}$ to complete. The respondents were also reminded to complete it by themselves and not discuss it with other friends during the completion of the research scales. All results of the scale completion were also considered true as long as it was relevant to the condition of each respondent. After completing all the scales in the form of Google form, the collected data as the raw data were ready to be processed for further analysis.

\section{Measurement}

The study on the influence of parenting and friendship on self-esteem in adolescents was revealed through the three measurement scales. The three measurement scales consisted of the Parenting Scale, Friendship Scale, and Self-Esteem Scale.

\section{Self-esteem}

Self-esteem measurement in adolescents in this study used the modification of the Self-Esteem Scale by Cooper Smith. The Self-Esteem Scale consisted of 29 items enclosing 4 aspects. The four aspects were personal interest, peers, school, dan parents.

\section{Parenting}

In this study, the measurement of parenting in adolescents used the modification of Parenting Scale in adolescents developed by Sanders. This Parenting Scale comprised of 3 aspects, namely the parents' cooperation, being tolerant with children, and being warm in interacting. The three aspects were revealed using 22 question items.

\section{Friendship}

The friendship, in this study, was revealed using the modification of the Friendship Scale in adolescents by Parker Asher. The Friendship Scale in adolescents consisted of 6 aspects. The six aspects were support and care, companionship and recreation, help and guidance, intimate exchanges, conflict and betrayal, and conflict resolution. The six aspects were developed into 26 question items.

\section{Validity and reliability}

Validity is a measure that shows the levels of validity of an instrument. To achieve the validity of the research instrument used in this study, the instrument was validated by an expert, namely professional judgment. Then, the Initial Scale was tested on a small group of subjects, namely 32 subjects. Furthermore, the researcher tried to see if the items on the scale had difficulties in using words, language or incorrect answer choices. The conclusion is that the invalid items in the validity test obtained from the SPSS program analysis were 9 items including items number 16, 17, 27, 30, 33, $40,42,51$, and 57 so that the total valid items in this learning motivation psychological scale are 51 items. Meanwhile, the reliability test showed that the scale is above the threshold so it is declared to be reliable.

\section{Objective and hypothesis}

\section{Objective}

This study, partially, aimed at examining:

1. The influence of parenting on self-esteem in adolescents

2. The influence of friendship on self-esteem in adolescents.

In general, this study aimed at measuring the influence of parenting and friendship on self-esteem in adolescents.

\section{Hypothesis}

The major or primary hypothesis proposed in this study was that parenting and friendship simultaneously influenced self-esteem in adolescents. Besides, the minor hypotheses were:

1. Parenting influences self-esteem in
adolescents
2. $\begin{aligned} & \text { Friendship influences self-esteem in } \\ & \text { adolescents. }\end{aligned}$

\section{Data analysis}

This study consisted of two independent variables and one dependent variable. The independent variables were parenting and friendship that were assumed simultaneously or partially influence selfesteem in adolescents. With this assumption, this study used multiple regression analysis to test the proposed hypotheses.

The use of the multiple regression analysis fulfilled some assumptions, namely:

\section{Normality Test}

The assumption that should be fulfilled was the normally distributed regression model.

2. Linearity Test

The relationship that was partially formed between the independent variables and the dependent variable was linear.

3. Multicollinearity Test

In the regression model, there was no multicollinearity symptom.

4. Heteroscedasticity Test

In the regression model, there was no heteroscedasticity symptom. 
5. Autocorrelation Test

In the regression model, there was no autocorrelation symptom.

\section{Normality test}

The hypotheses of normality test

Ho: The data were normally distributed

Ha: The data were not normally distributed Decisions:

a. If the significance value (Sig.) was more than 0.05 , the data were normally distributed

b. If the significance value (Sig.) was less than 0.05 , the data were not normally distributed.

Based on the result of the Normality Test, it obtained

a. A significance value (Sig.) for Parenting (X1) of $0.78>0.05$, indicating that parenting is normally distributed

b. A significance value (Sig.) for Friendship (X2) of $0.86>0.05$, indicating that the data for Friendship were normally distributed

c. A significance value (Sig.) for Self-Esteem (Y) of $0.85>0.05$, indicating that the data for parenting were normally distributed.

\section{Linearity test}

The foundation of decision-making for linearity test

a. The probability of a significance value (Sig.) of $>0.05$, indicating that no difference in the linearity between independent variables and dependent variables/there is a linear relationship between independent variables and dependent variables

b. The probability of a significance value (Sig.) $<0.05$, indicating that there is a difference in the linearity between independent variables and dependent variables/there is no linear relationship between independent variables and dependent variables.

Based on the result of the linearity, it obtained a significance value (Sig.) for Deviation from Linearity of $0.227>0.05$, indicating that there was a linear relationship between independent variables and dependent variables.

\section{Multicollinearity test}

The foundations of decision-making in the multicollinearity test using the tolerance and VIF were as follows:

The guideline of decision-making based on the tolerance value:

a. If the tolerance value is more than 0.10 , there is no multicollinearity in the regression model b. If the tolerance value is less than 0.10 , there is multicollinearity in the regression model.

The guideline of decision-making based on the VIF (Variance Inflation Factor) value

a. If the VIF value is less than 0.10 , there is no multicollinearity in the regression model

b. If the VIF value is more than 0.10 , there is multicollinearity in the regression model.

Table 1: Multicollinearity in the regression model

\begin{tabular}{llll} 
Coefficients $^{\mathrm{a}}$ & & & \\
\hline Model & & Collinearity Statistics & \\
\cline { 3 - 4 } & & Tolerance & VIF \\
\hline 1 & $\mathrm{X} 1$ & 0.953 & 1.050 \\
& $\mathrm{X} 2$ & 0.953 & 1.050 \\
\hline${ }^{a}$ Dependent Variable: $\mathrm{Y}$ & & &
\end{tabular}

Based on the result of the multicollinearity test, it obtained a tolerance value for Parenting (X1) of 0.953 $>0.01$, and the VIF value for Parenting (X1) of $1.050<$ 10.00 , indicating that there was multicollinearity.

Based on the result of the multicollinearity test, it obtained a tolerance value for Friendship (X2) of 0.953 $>0.01$, and the VIF value for Friendship (X2) of 1.050 $<10.00$, indicating that there was no multicollinearity.

Based on the result of the multicollinearity test, it is obvious that there was no multicollinearity between Parenting (X1) and Friendship (X2) against Self-Esteem (Y).

\section{Heteroskedasticity test}

The foundations of decision-making in the heteroscedasticity test are as follows:

a. The probability of a significance value (Sig.) of $>0.05$ indicates that there is no heteroscedasticity symptom

b. The probability of a significance value (Sig.) of $<0.0505$ indicates that there is heteroskedasticity symptom.

Based on the result of the heteroskedasticity test, it obtained a significance value (Sig.) for Parenting (X1) of $0.0729>0.05$, and for Friendship (X2) of 0.369 $>0.05$, indicating that there is no heteroskedasticity.

\section{Autocorrelation test}

The foundations of decision-making in the Autocorrelation test by Durbin-Watson

1. If the $d$ (Durbin-Watson) value is less than $\mathrm{dL}$ or more than $(4-\mathrm{dL})$, the null hypothesis is rejected, indicating that there is autocorrelation

2. If the $d$ (Durbin-Watson) value is in between $d U$ and $(4-\mathrm{dU})$, the null hypothesis is accepted, indicating that there is no autocorrelation

3. If the $\mathrm{d}$ (Durbin-Watson) value is in between $\mathrm{dL}$ and $\mathrm{dU}$ or in between $(4-\mathrm{dU})$ and $(4-\mathrm{dL})$, it does not generate a certain conclusion. 
Based on the result of the Durbin-Watson table for (variables, samples) --> $(3,171)$, the dU value of 1.7856 , and the $(4-\mathrm{dU})$ value is $4-1.7856$ or equals to 3.2144 ; as the foundation of decision-making in the autocorrelation test. Based on the result of the autocorrelation test by Durbin-Watson, it obtained a Durbin-Watson value of 2.020. The value was in between the $\mathrm{dU}$ value of 1.7856 and the $(4-\mathrm{dU})$ of 3.2144 . Therefore, it indicates that there was no autocorrelation.

Based on the data shown above, the five assumptions have been fulfilled.

\section{Multiple linear regression test}

The data analysis in this study used the multiple linear regression test. This test consisted of a $\mathrm{t}$-test and $\mathrm{F}$-test with a difference in the significance of the influence given by the $X$ variable to the $Y$ variable whether it is separated or combined.

a. The t-test functions to know the partial influence of the $X$ variable on the $Y$ variable which is aimed to test the minor hypothesis $r$

b. The F-test is aimed to know the simultaneous influence of the $X$ variable (simultaneous or associated) on the $Y$ variable or the major hypothesis.

\section{F-test}

\section{The major hypothesis testing through the}

The first step of the hypothesis testing in this study was comparing the significance value (Sig.) or the probability value from the ANOVA output. Meanwhile, the second step was comparing the calculated- $F$ value with the tabulated-F value.

1. Based on the significance value (Sig.) of the ANOVA output

a. If the Sig. value is $<0.05$, the hypothesis is accepted. It indicates that Parenting (X1) and Friendship (X2) simultaneously influence Self-Esteem ( $Y$ )

b. If the Sig. value is $>0.05$, the hypothesis is rejected. It indicates that Parenting (X1) and Friendship (X2) simultaneously do not influence Self-Esteem $(Y)$.

2. Based on the comparison of the calculated- $\mathrm{F}$ value against the tabulated- $F$ value

a. If the calculated- $F$ value is $>$ than the tabulated-F value, the hypothesis is accepted. It indicates that Parenting (X1) and Friendship (X2) simultaneously influence Self-Esteem $(Y)$, and vice versa

b. If the calculated- $F$ value is < than the tabulated-F value, the hypothesis is rejected. It indicates that Parenting (X1) and Friendship (X2) simultaneously do not influence Self-Esteem (Y).

\section{Results}

From the result of the data analysis, it was obtained that:

1. Based on the significance value (Sig.) of the ANOVA output, it showed that the Sig. value was $0.046<0.05$. It indicates that Parenting (X1) and Friendship (X2) simultaneously influence Self-Esteem ( $Y$ )

Or from the result of

2. The comparison of the calculated- $F$ value against the tabulated- $F$ value.

The calculated- $F$ value of 3.729 is > than the tabulated-F value of 3.05 , indicating that Parenting (X1) and Friendship (X2) simultaneously influence SelfEsteem (Y).

research

\section{Respondent characteristics from this}

\section{By Gender}

Table 2: Respondent characteristics from this research by gender

\begin{tabular}{lll} 
By Gender & & \\
\hline Gender & Amount & Presentation \\
\hline Male & 33 & $24 \%$ \\
Woman & 140 & $76 \%$ \\
& 173 & $100 \%$ \\
\hline
\end{tabular}

By Age

Table 3: Respondent characteristics from this research by age

\begin{tabular}{lll} 
By Age & & \\
\hline Gender & Amount & Presentation \\
\hline $13-17$ years old & 173 & $100 \%$ \\
\hline
\end{tabular}

The influence of Parenting (X1) and Friendship (X2) on Self-Esteem (Y).

Based on the significance value (Sig.).

a. If the Sig. value is $<0.05$, the hypothesis is accepted. It indicates that Parenting (X1) and Friendship (X2) simultaneously influence SelfEsteem (Y)

b. If the Sig. value is $>0.05$, the hypothesis is rejected. It indicates that Parenting (X1) and Friendship (X2) do not simultaneously influence Self-Esteem ( $Y$ ).

Based on the significance value (Sig.) of the ANOVA output, it showed that the Sig. value was 0.046 $<0.05$. It indicates that Parenting $(X 1)$ and Friendship $(\mathrm{X} 2)$ simultaneously influence Self-Esteem $(\mathrm{Y})$. Based on the table above, it is obvious that Parenting (X1) and Friendship (X2) influence Self-Esteem $(\mathrm{Y})$ by 0.32 or $32 \%$.

Hence, the result above obtained that the multiple linear regression equation is as follows. 
$\hat{Y}=0.101 X 1+0.102 X 2+56.755+E r r o r$

It means that the addition of 1 unit of Parenting (X1) and 1 unit of Friendship (X2) will affect the addition in Self-Esteem (Y) of 0.203.

\section{The minor hypothesis testing}

1. The influence of Parenting (X1) on Self-esteem (Y).

Based on the result of the data analysis, it obtained:

1. Based on the significance value (Sig.) of the ANOVA output, it showed that the Sig. value was $0.046<0.05$. It indicates that Parenting (X1) simultaneously influences Self-Esteem (Y)

Or from the result of

2. The comparison of the calculated- $F$ value against the tabulated- $F$ value

The calculated- $F$ value of 4.346 was $>$ than the tabulated-F value of 3.90 , indicating that Parenting (X1) simultaneously influences Self-Esteem $(\mathrm{Y})$.

Based on the result shown above, it was obtained that the linear regression equation in the calculation that had been done was as follows.

$$
\hat{Y}=0.67 \times 1+4.899+\text { Error }
$$

It shows that the addition of 1 unit of Parenting (X1) will be able to increase Self-Esteem (Y) by 4.889 .

In addition, the degree of influence can be seen in the table below.

\section{Table 4: Degree of influence}

Model Summary \begin{tabular}{lllll}
\hline Model & $\mathrm{R}$ & $\mathrm{R}$ Square & Adjusted R Square & Std. Error of the Estimate \\
\hline 1 & $0.139^{\mathrm{a}}$ & 0.029 & 0.024 & 4.40133 \\
\hline
\end{tabular} 1. Based on the the table above, it can be seen that the degree of influence by Parenting $(\mathrm{X} 1)$ against Self-Esteem $(Y)$ is $R_{\text {square }}$ of 0.29 or $29 \%$.

2. The Influence of Friendship (X2) on SelfEsteem (Y).

Based on the result of the data analysis, it obtained:

1. Based on the significance value (Sig.) of the ANOVA output, it showed that the Sig. value was $0.037<0.05$. It shows that Friendship (X2) simultaneously influences Self-Esteem $(\mathrm{Y})$ Or from the result of

2. The comparison of the calculated- $F$ value against the tabulated- $F$ value.

The calculated- $F$ value of 4.280 was > than the tabulated- $F$ value of 3.90 , indicating that Friendship (X2) simultaneously influences SelfEsteem $(\mathrm{Y})$.
From the result shown above, it was obtained that the linear regression equation in the calculation that had been done was as follows.

$$
\hat{Y}=0.69 \times 2+4.111+\text { Error }
$$

It shows that the addition of 1 unit of Friendship (X2) will be able to increase Self-Esteem (Y) by 4.111. In addition, the degree of influence can be seen in the table below.

Table 5: the degree of influence after addition of 1 unit

\begin{tabular}{llllll}
\multicolumn{2}{l}{ Model Summary ${ }^{\mathrm{b}}$} & \multicolumn{2}{l}{$l$} & \\
\hline Model $\mathrm{R}$ & $\mathrm{R}$ Square & $\begin{array}{l}\text { Adjusted } \\
\mathrm{R} \text { Square }\end{array}$ & $\begin{array}{l}\text { Std. Error of the } \\
\text { Estimate }\end{array}$ & Durbin-Watson \\
\hline 1 & $0.138^{\mathrm{a}}$ & 0.129 & 0.132 & 4.40217 & 2.022 \\
\hline${ }^{\mathrm{a}}$ Predictors: (Constant), X2. ${ }^{\mathrm{b}}$ Dependent Variable: $\mathrm{Y}$ & &
\end{tabular}

From the table above, it can be seen that the degree of influence by Friendship (X2) against SelfEsteem ( $Y$ ) is $R_{\text {Square }}$ of 0.129 or $12.9 \%$.

\section{Results}

\section{Descriptive result}

Table 6: Descriptive results

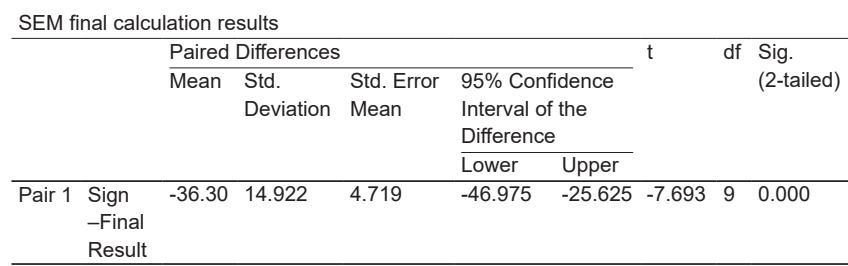

\section{Multivariate result}

The major or primary hypothesis proposed in this study was that parenting along with friendship simultaneously influence self-esteem in adolescents. The result of the multiple linear regression analysis for testing those hypotheses is presented in the table below.

Based on the result of the data analysis, it obtained:

1. Based on the significance value (Sig.) of the ANOVA output, it showed that the Sig. value was $0.046<0.05$. It indicates that Parenting (X1) and Friendship (X2) simultaneously influence Self-Esteem (Y).

Or from the result of

2. The comparison of the calculated- $F$ value against the tabulated- $\mathrm{F}$ value.

The calculated- $F$ value of 3.729 was $>$ than the tabulated- $F$ value of 3.05 , indicating that Parenting (X1) and Friendship (X2) simultaneously influence SelfEsteem (Y). 
It means that Parenting (X1) and Friendship

(X2) simultaneously influence Self-Esteem (Y).

\section{The result of the minor hypothesis testing}

Minor Hypothesis 1: The Influence of Parenting (X1) on Self-Esteem (Y).

From the result of the data analysis, it obtained:

1. Based on the significance value (Sig.) of the ANOVA output, it showed that the Sig. value was $0.046<0.05$. It indicates that Parenting (X1) simultaneously influences Self-Esteem $(\mathrm{Y})$

2. The comparison of the calculated- $F$ value against the tabulated- $F$ value. The calculated- $F$ value of 4.346 was $>$ than the tabulated-F value of 3.90 , indicating that Parenting (X1) simultaneously influences Self-Esteem $(\mathrm{Y})$.

The result of the data analysis is seen in the table below.

\begin{tabular}{|c|c|c|c|c|c|c|}
\hline \multicolumn{7}{|c|}{ Coefficients $^{a}$} \\
\hline \multicolumn{2}{|c|}{ Model } & \multicolumn{2}{|c|}{$\begin{array}{l}\text { Unstandardized } \\
\text { Coefficients }\end{array}$} & \multirow{2}{*}{$\begin{array}{l}\text { Standardized Coefficients } \\
\text { Beta }\end{array}$} & \multirow[t]{2}{*}{ t } & \multirow[t]{2}{*}{ Sig. } \\
\hline & & B & $\begin{array}{l}\text { Std. } \\
\text { Error }\end{array}$ & & & \\
\hline 1 & (Constant) & 61.253 & 4.899 & & 12.503 & 0.000 \\
\hline & & 0.122 & 0.067 & 0.139 & 2.982 & 0.046 \\
\hline 2 & Anova & 63.562 & 4.280 & & $0.037^{\mathrm{b}}$ & \\
\hline 3 & Sumarry & 0.129 & 0.132 & 4.40217 & 2.022 & \\
\hline
\end{tabular}

From the result shown above, it was obtained that the linear regression equation as follows.

$$
\hat{Y}=0.67 \times 1+4.899+E r r o r
$$

It shows that the addition of 1 unit of Parenting (X1) will be able to increase self-esteem (Y) by 4.889 . In addition, the degree of influence can be seen in the table below. Based on the table above, it can be seen that the degree of influence by Parenting (X1) against self-esteem $(Y)$ is $R_{\text {square }}$ of 0.29 or $29 \%$. Based on the result of the data analysis, it obtained:

1. Based on the significance value (Sig.) of the ANOVA output, it showed that the Sig. value was $0.037<0.05$. It indicates that Friendship (X2) simultaneously influences self-esteem $(Y)$

2. The comparison of the calculated- $F$ value against the tabulated- $F$ value. The calculated- $F$ value of 4.280 was $>$ than the tabulated- $F$ value of 3.90 , indicating that friendship (X2) simultaneously influences self-esteem $(Y)$.

From the result shown above, it was obtained that the linear regression equation as follows.

$$
\hat{Y}=0.69 \times 2+4.111+\text { Error }
$$

It shows that the addition of 1 unit of Friendship $(\mathrm{X} 2)$ will be able to increase Self-Esteem $(Y)$ by 4.111. Moreover, the degree of influence can be seen in the table below.

From the table above, it can be seen that the degree of influence by Friendship (X2) against SelfEsteem $(Y)$ is $R_{\text {square }}$ of 0.129 or $12.9 \%$.

\section{Discussion}

The objective of this study was to identify the simultaneous influence of parenting and friendship on selfesteem in adolescents. Based on the result of the major hypothesis testing, it is known that Parenting (X1) and Friendship (X2) simultaneously influence Self-Esteem (Y); with Sig. Value of $0.046<0.05$ and the calculated-F value of $4.346>$ the tabulated-F value of 3.90 .

The result of this study is in line with the statement of the previous research (Ahmed et al., 2020) that personality development, including individual selfesteem, is always influenced by interaction with its social situation. Self-esteem as a part of self-concept always grows and develops (Measures Self-Esteem, Chiu, 1988.Pdf, n.d.) started from the family. Family plays a vital role in human development, especially during childhood and adolescence. The family factor referring to the family structure, parents' discipline, parentschildren relationship, communication with parents, and education or occupation, as well as family status [15] significantly influence self-esteem development in children who grow up in the family.

The influence of social family in structuring self-esteem occurs during childhood and increases until adolescence [1] Furthermore, another study [16] also stated that self-esteem development was influenced by several social contexts. The first social context affecting self-esteem in adolescents is family. The parents' communication pattern in their positive parenting directly affects self-esteem formation in adolescents. The parents are the first place affecting the formation and the development of self-esteem in adolescents [17]. The quality of the parents-children relationship will strongly determine the quality of interaction in it [18].

The result of this study also showed how the emotional connection, warmth, and the way to communicate will strongly determine the personality development in adolescents, including their selfesteem. The previous studies also reinforced that a poor relationship in parenting will affect the way adolescents form their self-esteem [19].

The hypotheses also showed that self-esteem formation in adolescents through parenting was 
simultaneously reinforced by the adolescents' relations with their friends from the fellowship. Self-competency, self-confidence, self-esteem, and all characters in adolescents are simultaneously affected by the family relationship and the friendship model they have. The adolescents' mental health quality, especially about how the adolescents appreciate themselves, is the result of an interaction with the social support relation of the pertinent individual [20].

Partially, this study also tried to empirically examine the influence of parenting on self-esteem in adolescents; and the influence of friendship on selfesteem in adolescents. Furthermore, this study also tried to examine the parenting indicator consisting of parents' cooperation, being tolerant with children, and warmth; and the friendship indicator consisting of support/care, recreation, help and guidance, intimate exchanges, conflict and betrayal, and conflict resolution, that were associated with self-esteem in adolescents consisting of personal interest, friendship, school, and parent [11].

The result of this study showed a significant and positive influence of parenting against self-esteem in adolescents. This finding was in line with the theory stated by Brofenbrener that human development is affected by the socio-environmental context. The reciprocal relationship between individuals with the environment will form the individual's behavior. The environment of the children's domicile is the first and the primary place to illustrate the children's personality development. Wrong parenting style, abandoned children, and domestic violence will affect the mental health during adolescence, especially in their selfesteem [15], [21]. Therefore, the parents' behavior as the representation of the parents' mental conditions will form self-esteem in adolescents. Furthermore, adolescence is the period of unique life development that is characterized by the transition from childhood to adolescence. Adulthood whereby the adolescents should adapt themselves to various changes and challenges, and this may make the adolescents susceptible to their psychosocial problems so that, in this case, the basic foundation of positive parenting from parents is required [7]. The studies also showed that support from certain reliable individuals (adults) who act responsibly will affect the comfort of life and self-esteem in adolescents [16], [22].

Self-esteem in adolescents develops along with their interest in developing their social function. In the socialization with their friends, adolescents begin to develop their self-esteem or how far they appreciate or and feel comfortable with themselves. For instance, an adolescent who feels that he/she is attractive can accept themselves and their physical appearance just the way they are, with a tendency to judge themselves as positive up to mature will develop as a popular adolescent [9], [23].

The previous studies also reinforced how the adolescents developed their self-esteem through friendship and companionship, either school friends or playmates. During adolescence, the children start to be able to compare their skills to their peers. Entering the adolescent age, the most vital issue is seeking self-identity. According to Erikson, identity is a coherent conception about the "self" that is formed according to the purpose, values, and beliefs that are believed by oneself. Adolescents have a broader social environment so that the judgment from people that mean a lot to them besides parents, such as peer group, certainly and significantly affect their self-esteem and competencies [4]. Self-identity is inextricably linked to self-esteem [19].

\section{Conclusion}

This study partially aims to examine the influence of parenting on self-esteem in adolescents and the influence of friendship on self-esteem in adolescents. Moreover, this study generally aims to measure the influence of parenting along with friendship on self-esteem in adolescents.

The result of this study shows a positive and significant influence of parenting and friendship on self-esteem in adolescents. Separately, this study also proves that parenting influences self-esteem in adolescents. This study also proves that friendship significantly influences their self-esteem.

\section{Acknowledgments}

The authors would like to thank senior high school in Semarang Central Java Indonesia, Yayasan Alumni Undip, LPPM Universitas Semarang and Rector Universitas Semarang

\section{References}

1. Pazzaglia F, Moè A, Cipolletta S, Chia M, Galozzi P, Masiero S et al. Multiple dimensions of self-esteem and their relationship with health in adolescence. Int J Environ Res Public Health. 2020;17(8):2616. http://doi.org/10.3390/ijerph17082616 PMid:32290357

2. Sugiarti R, Suhariadi F, Erlangga E. The chance of gifted intelligent students' success in career. Indian J Public Health Res Dev. 2018;9(9):277. http://doi.org/10.5958/0976-5506.2018.01009.4

3. Henley L, Lickona T. Moral development and behavior: Theory, research, and social issues. Fam Coord. 1976;25(5):582353.

4. Sugiarti R, Erlangga E. Correlation between parenting and anxiety on higher achiever students. J Din Sos Budaya. 
2017;19(1):688. https://doi.org/10.26623/jdsb.v19i1.688

5. Sugiarti R, Riana R, Erlangga E. Influence of Group Counseling on Gifted Students' Argument Skill; 2020. https://doi. org/10.2991/assehr.k.200318.016

6. Keizer R, Helmerhorst KO, van Rijn-van Gelderen L. Perceived quality of the mother-adolescent and father-adolescent attachment relationship and adolescents' self-esteem. J Youth Adolesc. 2019;48(6):1203-17. https://doi.org/10.1007/ s10964-019-01007-0

PMid:30887261

7. Banstola RS, Ogino T, Inoue S. Impact of parents' knowledge about the development of self-esteem in adolescents and their parenting practice on the self-esteem and suicidal behavior of urban high school students in Nepal. Int J Environ Res Public Health. 2020;17(17):6039. https://doi.org/10.3390/ ijerph17176039

PMid:32825158

8. Chung GH, Lee J, Gonzales-Backen M. Context of biethnic acceptance, biethnic affirmation, and life satisfaction among Korean biethnic adolescents. J Adolesc. 2020;80:242-53. https://doi.org/10.1016/j.adolescence.2020.03.004 PMid:32213380

9. Harris MA, Orth $U$. The link between self-esteem and social relationships: A meta-analysis of longitudinal studies. J Pers Soc Psychol. 2020;119(6):1459-77. https://doi.org/10.1037/ pspp0000265 PMid:31556680

10. Ahmed S, Foulkes L, Leung JT, Griffin C, Sakhardande A, Bennett $\mathrm{M}$, et al. Susceptibility to prosocial and antisocial influence in adolescence. J Adolesc. 2020;84:56-68. https://doi. org/10.1016/j.adolescence.2020.07.012 PMid:32858504

11. Raboteg-Saric Z, Sakic M. Relations of parenting styles and friendship quality to self-esteem, life satisfaction and happiness in adolescents. Appl Res Qual Life. 2014;9(3):749-65.

12. Alm S, Låftman SB, Sandahl J, Modin B. School effectiveness and students' future orientation: A multilevel analysis of upper secondary schools in Stockholm, Sweden. JAdolesc. 2019;70:6273. https://doi.org/10.1016/j.adolescence.2018.11.007

13. Parkes A, Wight D, Hunt K, Henderson M, Sargent J. Are sexual mediaexposure, parental restrictions onmediauseandco-viewing TV and DVDs with parents and friends associated with teenagers' early sexual behaviour? J Adolesc. 2013;36(6):1121-33. https://doi.org/10.1016/j.adolescence.2013.08.019 PMid:24215959

14. Chiu LH. Measures of self-esteem for school-age children. J
Counseling Dev 1988;66(6):298.

15. Chung HW, Kim EM, Lee JE. Comprehensive understanding of risk and protective factors related to adolescent pregnancy in low and middle-income countries: A systematic review. J Adolesc. 2018;69:180-8. https://doi.org/10.1016/j. adolescence.2018.10.007

PMid:30390598

16. den Boer L, Klimstra TA, Denissen JJA. Associations between the identity domains of future plans and education, and the role of a major curricular internship on identity formation processes. J Adolesc. 2021;88:107-19. https://doi.org/10.1016/j. adolescence.2021.02.005

17. Schoon I, Burger K, Cook R. Making it against the odds: How individual and parental co-agency predict educational mobility. J Adolesc. 2021;89(2):74-83. https://doi.org/10.1016/j. adolescence.2021.04.004

18. Shek DT, Chai CW, Dou D. Parenting factors and meaning of life among Chinese adolescents: A six-wave longitudinal study. J Adolesc. 2021;87:117-32. https://doi.org/10.1016/j. adolescence.2021.01.004 PMid:33581398

19. Hollarek M, Lee NC, Krabbendam L. The effect of socia feedback from peers on adolescent cognitive control. J Adolesc. 2020;85:12-20. https://doi.org/10.1016/j. adolescence.2020.09.010

20. Jenkins EK, Bungay V, Patterson A, Saewyc EM, Johnson JL. Assessing the impacts and outcomes of youth driven mental health promotion: A mixed-methods assessment of the social networking action for resilience study. J Adolesc. 2018;67:1-11. https://doi.org/10.1016/j.adolescence.2018.05.009 PMid:29859474

21. Thoma MV, Bernays F, Eising CM, Maercker A, Rohner SL. Child maltreatment, lifetime trauma, and mental health in Swiss older survivors of enforced child welfare practices: Investigating the mediating role of self-esteem and self-compassion. Child Abus Negl. 2021;113:104925. https://doi.org/10.1016/j. chiabu.2020.104925

PMid:33461114

22. Shofwan I, Sugiarti R, Erlangga E, Yogatama A, Hariningsih. Indicator of teacher work stress. Int $\mathrm{J}$ Sci Technol Res. 2019;8(12):8633.

23. Cortina MA, Stein A, Kahn K, Hlungwani TM, Holmes EA, Fazel M. Cognitive styles and psychological functioning in rural South African school students: Understanding influences for risk and resilienceintheface of chronicadversity. JAdolesc. 2016;49:38-46. https://doi.org/10.1016/j.adolescence.2016.01.010 